\title{
Effect in the Cow of Intraruminal Infusions of Volatile Fatty Acids and of Lactic Acid on the Secretion of the Component Fatty Acids of the Milk Fat and on the Composition of Blood
}

\author{
BY J. E. STORRY AND J. A. F. ROOK \\ National Institute for Research in Dairying, Shinfield, Reading, Berks.
}

(Received 11 November 1964)

\begin{abstract}
1. The effects in the cow of intraruminal infusions of acetic acid, propionic acid or butyric acid on the secretion of the component fatty acids of the milk fat, and of these acids and of lactic acid on the composition of the blood plasma of the jugular vein, have been studied. 2. The infusion of acetic acid or butyric acid increased the yield of the $\mathrm{C}_{4}-\mathrm{C}_{16}$ acids of milk fat but decreased the yield of $\mathrm{C}_{18}$ acids. The infusion of propionic acid decreased the yields of all major component acids except palmitic acid and possibly lauric acid. 3. The changes in the concentrations in blood plasma of glucose and of ketone bodies were consistent with the glucogenic effect of propionic acid and the ketogenic effects of butyric acid and acetic acid. The effects of lactic acid were not consistent from cow to cow. Only with the infusion of acetic acid was a significant increase in the concentration of total volatile fatty acids in blood plasma found. Infusions of butyric acid and of propionic acid tended to depress the concentration of citric acid in the blood plasma and infusion of acetic acid increased it. No consistent effects of the infused acids on the concentration in blood plasma of esterified cholesterol, free cholesterol, triglyceride or phospholipid were observed. 4. The possibility is discussed that the effects of the infused acids on milk-fat secretion are caused through an alteration of the concentrations of precursors of milk fat in mammary arterial blood.
\end{abstract}

Intraruminal infusions of volatile fatty acids in milking cows have been shown to have characteristic effects on milk-fat secretion; acetic acid and butyric acid increase the yield, whereas propionic acid decreases it (Rook \& Balch, 1961; Rook, Balch \& Johnson, 1965). To obtain information on the way in which these changes arise, the effects in lactating cows of intraruminal infusions of individual volatile fatty acids on the yields of the major fatty acids of milk fat and on the concentration in blood of some metabolites that are possibly of importance in milkfat synthesis have been determined. In one experiment the effects of a continuous intraruminal infusion of lactic acid on blood composition also was determined. Preliminary findings on certain aspects of the work on blood composition have been published previously (Storry \& Rook, 1961).

\section{EXPERIMENTAL}

Animals and their management. Lactating Friesian cows fitted with large permanent rumen fistulas were housed in an experimental byre in which the management routine was normal. The basal diet consisted of 14-16lb. of hay/day and a feed concentrate balanced for milk production given at a rate of 3-4lb./gallon of milk produced.

Experimental design. In the first series of experiments the effects of continuous intraruminal infusions of volatile fatty acids on the yield of the individual fatty acids of milk fat were determined. Acetic acid (1500 ml./day), propionic acid (1500 ml./day) and butyric acid $(750 \mathrm{ml}$./day) were each infused separately into two cows for periods of 1 week between initial and final control periods of the same length. Milk yield was recorded and samples of the milk were taken throughout the experiments. Weighted composite samples representing either a single day or, in certain experiments during the initial control period, 2 days were prepared. Samples were analysed for fat content and the fatty acid composition of the milk fat.

In the second, third and fourth series of experiments the effects of intraruminal infusions of volatile fatty acids and of lactic acid on blood composition were determined, and in the third series the changes in blood composition were related also to the observed changes in milk-fat content. For the second series of experiments, infusions of propionic acid $(1600 \mathrm{ml}$./day) or butyric acid $(1300 \mathrm{ml} . /$ day $)$ and of acetic acid $(1500 \mathrm{ml} . /$ day $)$ or lactic acid $(2000 \mathrm{ml}$./day) were compared with infusions of water only, according to a Latin-square design, in successive experiments with groups of three cows. The treatment periods were of 4 weeks' duration and, on the final day of each period, samples of blood from the jugular vein were taken through an indwelling polythene cannula at $0800,1000,1200,1400$, 1600 and 1800 hours.

In the third series of experiments, after a control period 
of 1 week, a daily amount of $500 \mathrm{ml}$. of butyric acid or of propionic acid was infused into the rumen and this was progressively increased until the animal began to refuse food. The addition of acid was then either stopped immediately or decreased for a day or two and then stopped. Milk yield was recorded and samples of milk were taken at each milking. Samples of blood from the jugular vein were taken through an indwelling polythene cannula at 0900, 1200 and 1500 hours on certain days during the control and experimental periods. Three experiments were done with propionic acid and five with butyric acid.

In the fourth series of experiments acetic acid, propionic acid and butyric acid were each infused separately in the same way as in the first series of experiments and blood samples were taken at 0900,1200 and 1500 hours on each of two consecutive days during the period of acid infusion and also during the control periods.

Intraruminal infusion of the acids. The acids were of technical grade. Acetic acid, butyric acid and propionic acid were 96-97\% pure and the main contaminants were other lower volatile fatty acids. The lactic acid $(80 \%, w / w)$ contained about $72 \%$ of lactic acid and $8 \%$ of lactide. The acids were diluted with 50-60 kg. of water and infused into the rumen by the technique of Rook \& Balch (1961).

Preparation of blood samples. A $0.5 \%$ solution of citrate in $0.9 \% \mathrm{NaCl}$ was injected into the indwelling polythene cannula as anticoagulant. When the citrate content of blood was to be determined, the citrate was replaced with heparin.

For analysis for lactic acid, pyruvic acid and $\alpha$-oxoglutaric acid an ice-cold-trichloroacetic acid filtrate of whole blood [ $1 \mathrm{vol}$. of blood to $5 \mathrm{vol}$. of $10 \%(\mathrm{w} / \mathrm{v})$ trichloroacetic acid solution] was prepared and then stored at $-20^{\circ}$. For all other analyses, plasma was separated immediately and extracted for lipid analysis or stored at $-20^{\circ}$ until required.

Blood plasma lipids. To $225 \mathrm{ml}$. of methanol (AnalaR grade; British Drug Houses Ltd., Poole, Dorset) in a glassstoppered flask were added $30 \mathrm{ml}$. of plasma $(10 \mathrm{ml}$. from each of three samples collected throughout a day) followed by $225 \mathrm{ml}$. of chloroform (AnalaR grade; British Drug Houses Ltd.) and the mixture was placed in a water bath at $60^{\circ}$ for $15 \mathrm{~min}$. The mixture was cooled to room temperature, a further $225 \mathrm{ml}$. of chloroform was added, and then the mixture was shaken vigorously and filtered through a fast filter paper (Whatman no. 541). The filter paper was then washed with sufficient methanol-chloroform $(1: 2, v / v)$ to bring the total volume of the filtrate to $750 \mathrm{ml}$. The lipid extract was purified by washing with $0.88 \% \mathrm{KCl}$ (Folch, Lees \& Sloane-Stanley, 1957) and dried to constant weight under a stream of nitrogen on a water bath at $50^{\circ}$.

The extracted lipids were separated on $3 \mathrm{~g}$. columns of silicic acid by the method of Barron \& Hannahan (1958) as adapted by Moore \& Doran (1962). The concentrations of the various major components of plasma lipid were calculated from the chemically determined cholesterol (Brown, 1959), glycerol (Moore, 1962) or phosphorus (Chen, Toribara \& Warner, 1958) content of the appropriate fractions. The triglycerides and cholesterol esters were expressed as the oleate and the phospholipid concentration was calculated by multiplying the determined $P$ by 25 . In this way contamina. tion of fractions with other compounds and with silicic acid was avoided (Storry \& Rook, 1964a).

The cholesterol esters, free cholesterol, triglycerides and phospholipids, determined as described, accounted for about $95 \%$ of the total lipid applied to the column.
Methods of analysis for other plasma constituents. The total steam-volatile fatty acids of plasma were determined by steam-distillation (Scarisbrick, 1952) and the acids in the distillate were separated by gas-liquid chromatography (Storry \& Millard, 1965). Details of other methods of analysis are as follows: ketone bodies (Reid, 1960), glucose (Somogyi, 1952), citric acid (McArdle, 1955), lactic acid (Barker \& Summerson, 1941; Pennington \& Sutherland, 1956) and pyruvic acid and $\alpha$-oxoglutaric acid (Friedman \& Haugen, 1943).

Extraction of milk lipids and determination of fatty acids. The fat from milk samples was extracted by the technique of Folch et al. (1957) (Storry \& Millard, 1965) and stored in methanol-chloroform $(1: 2, \mathrm{v} / \mathrm{v})$ under nitrogen until required for analysis. Then $150 \mathrm{ml}$. of the lipid solution was evaporated to dryness and the lipid hydrolysed with $10 \%(\mathrm{w} / \mathrm{v})$ $\mathrm{KOH}$ in methanol-water $(1: 1, v / v)$ under reflux for $3 \mathrm{hr}$. at $100^{\circ}$. The acids were recovered in light petroleum (b.p. $40-60^{\circ}$ ) and the methyl esters prepared by using methanolboron trifluoride in $\mathrm{H}_{2} \mathrm{SO}_{4}$ (Metcalfe \& Schmitz, 1961). The esters were analysed for $\mathrm{C}_{12}-\mathrm{C}_{20}$ acids by gas-liquid chromatography by using a Pye argon chromatograph (W. G. Pye and Co. Ltd., Cambridge). The relative proportions of the esters were determined from the retention times and peak heights by the method of Carroll (1961). Peaks were identified by comparison with authentic esters.

The remaining lipid was hydrolysed and the lower fatty acids were separated from the acidified solution by steamdistillation and analysed by gas-liquid chromatography (Storry \& Millard, 1965). The residual higher fatty acids were recovered and weighed.

\section{RESULTS}

\section{Effects of infusions on the yields of milk fat and of individual acids in milk fat}

The changes in the yield of milk fat observed in response to the intraruminal infusions of individual volatile fatty acids were consistent with previous results (Rook \& Balch, 1961 ; Rook et al. 1965). The mean changes \pm s.E.M. in fat yield, expressed as percentages of the original daily yield for each of the two cows, were $+8 \cdot 8 \pm 3 \cdot 1$ and $+6 \cdot 7 \pm 2 \cdot 6$ respectively with the infusion of acetic acid, $-12 \cdot 1 \pm 7 \cdot 5$ and $-13 \cdot 4 \pm 3 \cdot 5$ with the infusion of propionic acid and $+9 \cdot 3 \pm 3 \cdot 7$ and $+10 \cdot 1 \pm 5 \cdot 7$ with the infusion of butyric acid. The associated changes in the yields of the major component fatty acids of milk fat are given in Table 1. The patterns of response were the same in both cows. The infusions of acetic acid and of butyric acid had similar effects: the yields of $\mathrm{C}_{4}-\mathrm{C}_{16}$ acids were invariably increased, and to a similar extent, whereas, with the exception of the yield of $\mathrm{C}_{18: 2}$ acid plus $\mathrm{C}_{18: 3}$ acid in cow 1 , the yields of all the $\mathrm{C}_{18}$ acids were invariably depressed. During the infusion of propionic acid the yield of palmitic acid was unaltered, but the yields of all other major fatty acids, with the possible exception of lauric acid, were decreased. 
Table 1. Effects in lactating cows of intraruminal infusions of acetic acid, of propionic acid and of butyric acid on the yields of milk fat and of the major individual fatty acids of milk fat

Experimental details are given in the text. The designation of the fatty acids is according to the nomenclature of Dole, James, Webb, Rizack \& Sturman (1959).

\begin{tabular}{|c|c|c|c|c|}
\hline & Co & N 1 & Cor & $\mathbf{W} 2$ \\
\hline & $\begin{array}{c}\text { Mean yield } \\
\text { during control } \\
\text { periods (g./day) }\end{array}$ & $\begin{array}{c}\text { Percentage } \\
\text { change with } \\
\text { infusion of acid }\end{array}$ & $\begin{array}{c}\text { Mean yield } \\
\text { during control } \\
\text { periods (g./day) }\end{array}$ & $\begin{array}{r}\text { Percenta } \\
\text { change w } \\
\text { infusion of }\end{array}$ \\
\hline Acetic acid in & & & & \\
\hline Milk fat & 526 & +9 & 558 & +13 \\
\hline Fatty acid & & & & \\
\hline $4: 0$ & $12 \cdot 5$ & +22 & $14 \cdot 5$ & +5 \\
\hline $6: 0$ & $8 \cdot 6$ & +28 & $9 \cdot 7$ & +11 \\
\hline $8: 0$ & $5 \cdot 3$ & +27 & $6 \cdot 2$ & +17 \\
\hline $10: 0$ & 9.9 & +30 & $13 \cdot 0$ & +16 \\
\hline $12: 0$ & $16 \cdot 5$ & +5 & $16 \cdot 3$ & +26 \\
\hline $14: 0$ & $6 \cdot 2$ & +14 & 60.9 & +28 \\
\hline $16: 0$ & $149 \cdot 4$ & +25 & 141.9 & +38 \\
\hline 18:0 & $36 \cdot 7$ & -20 & 42.5 & -20 \\
\hline $18: 1 \mathrm{cis}$ & $109 \cdot 6$ & -20 & $101 \cdot 4$ & -21 \\
\hline 18:1 trans & $14 \cdot 3$ & -13 & $14 \cdot 1$ & -10 \\
\hline $\left.\begin{array}{l}18: 2 \\
18: 3\end{array}\right\}$ & $11 \cdot 7$ & +10 & $11 \cdot 7$ & -14 \\
\hline Propionic aci & ion & & & \\
\hline Milk fat & 770 & -13 & 753 & -12 \\
\hline Fatty acids & & & & \\
\hline 4:0 & $26 \cdot 0$ & -49 & $35 \cdot 3$ & -24 \\
\hline 6:0 & $22 \cdot 3$ & -48 & $25 \cdot 9$ & -30 \\
\hline 8:0 & $14 \cdot 7$ & -45 & $16 \cdot 0$ & $-\mathbf{3 3}$ \\
\hline $10: 0$ & $24 \cdot 9$ & -80 & $27 \cdot 0$ & -16 \\
\hline $12: 0$ & $31 \cdot 2$ & -20 & $26 \cdot 0$ & +6 \\
\hline $14: 0$ & $86 \cdot 5$ & -11 & $76 \cdot 6$ & -15 \\
\hline $16: 0$ & $209 \cdot 0$ & +1 & $228 \cdot 0$ & -2 \\
\hline $18: 0$ & $72 \cdot 0$ & -47 & $51 \cdot 0$ & -37 \\
\hline $18: 1 \mathrm{cis}$ & $138 \cdot 0$ & -27 & $144 \cdot 0$ & -28 \\
\hline 18:1 trans & $22 \cdot 4$ & -18 & $29 \cdot 0$ & -24 \\
\hline $\left.\begin{array}{l}18: 2 \\
18: 3\end{array}\right\}$ & $17 \cdot 1$ & -11 & $17 \cdot 7$ & -41 \\
\hline Butyric acid & & & & \\
\hline Milk fat & 691 & +7 & 951 & +3 \\
\hline Fatty acids & & & & \\
\hline $4: 0$ & $19 \cdot 3$ & +8 & $25 \cdot 2$ & +48 \\
\hline $6: 0$ & $14 \cdot 4$ & +20 & $18 \cdot 3$ & +54 \\
\hline $8: 0$ & $9 \cdot 4$ & +25 & $10 \cdot 7$ & +56 \\
\hline $10: 0$ & $15 \cdot 3$ & +31 & $17 \cdot 7$ & +13 \\
\hline $12: 0$ & $22 \cdot 6$ & +30 & $24 \cdot 0$ & +39 \\
\hline $14: 0$ & $64 \cdot 4$ & +30 & $78 \cdot 6$ & +39 \\
\hline $16: 0$ & 183.0 & +15 & $207 \cdot 5$ & +28 \\
\hline 18:0 & $49 \cdot 0$ & -6 & $61 \cdot 5$ & -6 \\
\hline $18: 1 \mathrm{cis}$ & $130 \cdot 0$ & -31 & $171 \cdot 0$ & -20 \\
\hline 18:1 trans & $24 \cdot 4$ & -11 & $25 \cdot 1$ & -14 \\
\hline $\left.\begin{array}{l}18: 2 \\
18: 3\end{array}\right\}$ & $17 \cdot 8$ & -24 & $18 \cdot 3$ & -12 \\
\hline
\end{tabular}

\section{Effects of intraruminal infusions on non-lipid} constituents of blood

Glucose and ketone bodies (Table 2). The infusion of butyric acid invariably caused an increase in the concentration of ketone bodies and a decrease in the concentration of glucose in the blood plasma, and acetic acid had a similar though smaller and less consistent effect. Conversely, propionic acid invariably increased the concentration of glucose and decreased that of ketone bodies, and lactic acid had no consistent effect. These effects of acetic acid, 


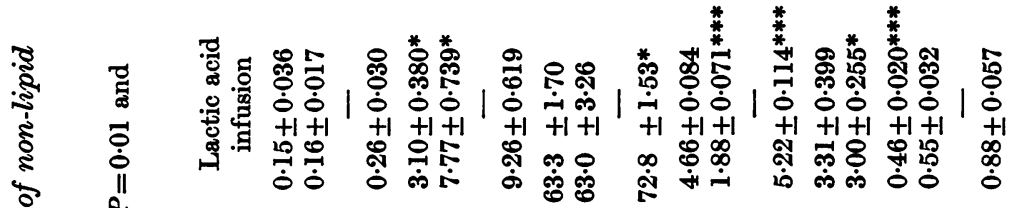

के

के

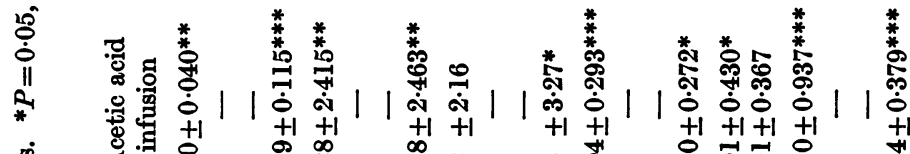

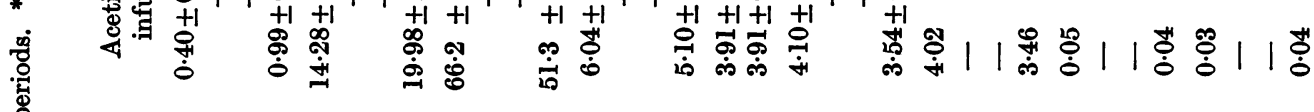

守

క్

惫

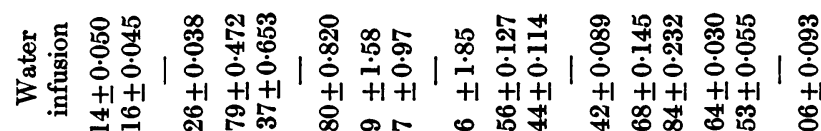

영잉

宽

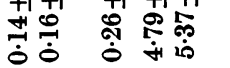

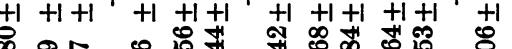

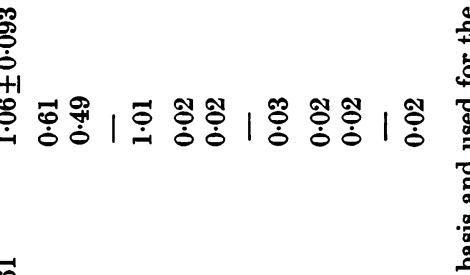

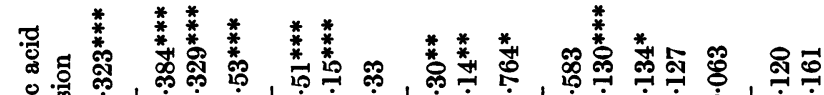

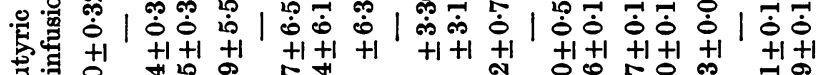

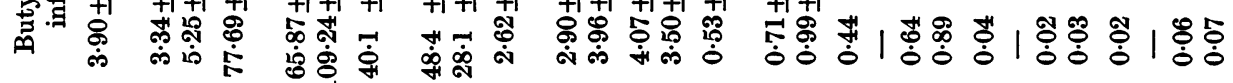

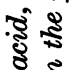

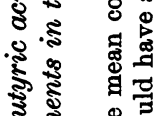

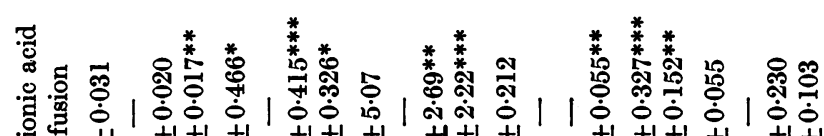

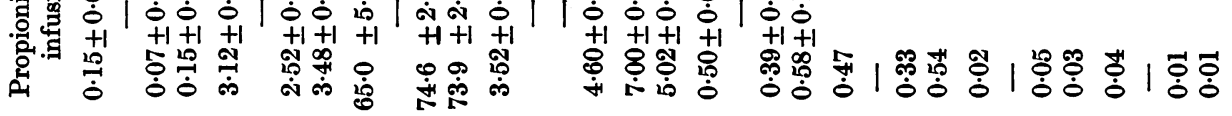

密要

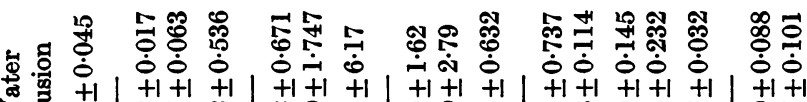

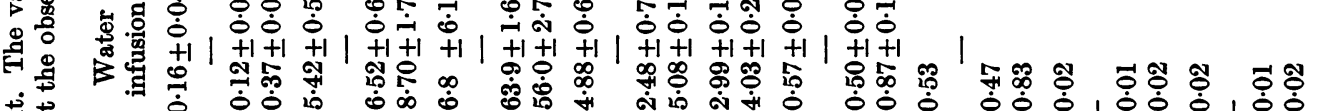

离弯

觢
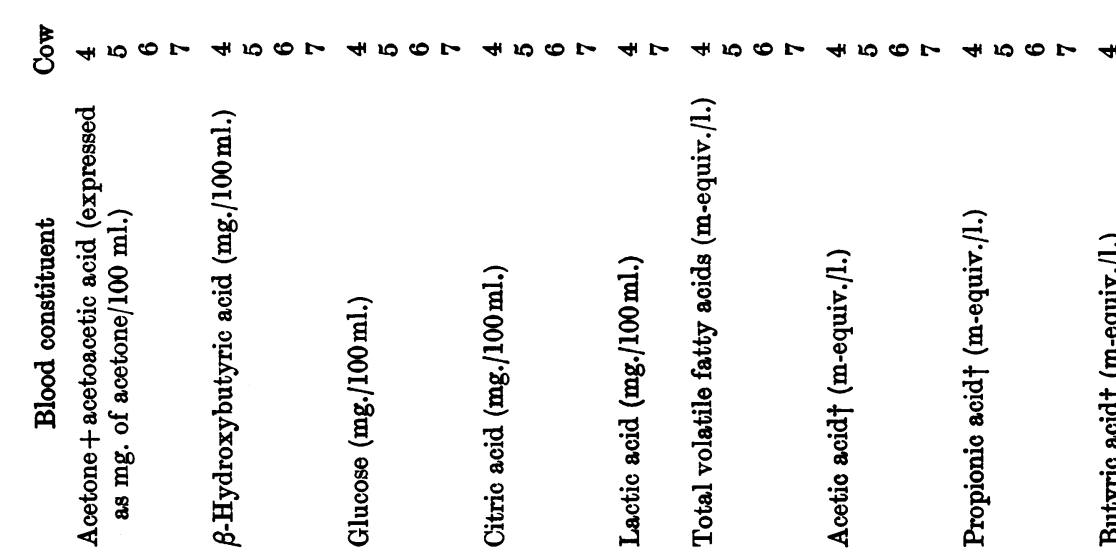

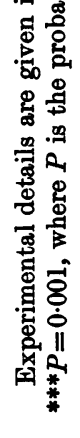

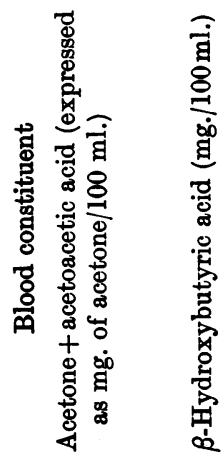

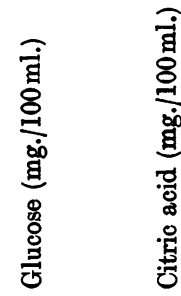

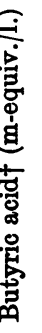


propionic acid and butyric acid in lactating cows are similar to those obtained in short-term experiments with starved sheep (Annison, Hill \& Lewis, 1957; Armstrong \& Blaxter, 1957; Clark \& Malan, 1956), goats (Schultz \& Smith, 1951; Johnson, 1955) and cows (Waldo \& Schultz, 1960). They are also in line with the conclusions of Annison, Leng, Lindsay \& White (1963) that, when labelled acids were infused into the portal vein of sheep, whereas propionate is glucogenic, butyrate and, to a less extent, acetate are ketogenic in their metabolism. The variable results obtained with lactic acid were probably related to the fact that in the rumen this acid is converted into a mixture of propionic acid and butyric acid (Hueter, Shaw \& Doetsch, 1956) and the composition of the mixture may vary from cow to cow.

Volatile fatty acids (Table 2). Acetic acid was the only acid infused that appeared itself in the plasma and caused a marked increase in the concentration of total volatile fatty acids. Propionic acid or butyric acid caused only small increases in their respective concentrations in the plasma, indicating that the added acids were almost completely metabolized in the rumen epithelium or in the liver. Propionic acid, however, depressed acetate concentration in the plasma, as found by Annison et al. (1963). In two cows, lactic acid also produced the same effect.

Citric acid (Table 2). The infusion of butyric acid caused a marked fall in the concentration of citric acid in blood plasma, and propionic acid tended to have a similar effect although the response was more variable. In contrast, acetic acid tended to increase the plasma citric acid concentration. Lactic acid had no consistent effect.

Lactic acid (Table 2). The lactic acid concentration in the blood plasma was increased consistently only by the infusion of propionic acid. Lactic acid production from propionic acid by sheep-liver slices has been demonstrated in vitro (Leng \& Annison, 1963).

Keto acids. In no instance did the intraruminal infusion of the volatile fatty acids produce a measurable change in the concentration of plasma keto acids.

The third series of experiments confirmed fully the effects on blood composition observed in the second series, and detailed results are therefore not reported. One important point that did emerge, however, was the variable degree to which animals responded to the infusion of acids, in terms both of the effects on blood composition and on fat yield. This is illustrated in Figs. 1 and 2 with results obtained with two cows, 8 and 9, giving a similar milk yield and maintained on a similar diet. Changes in $\beta$-hydroxybutyrate and glucose concentrations in blood plasma were much more marked in cow 9 with the infusion both of propionic acid and of

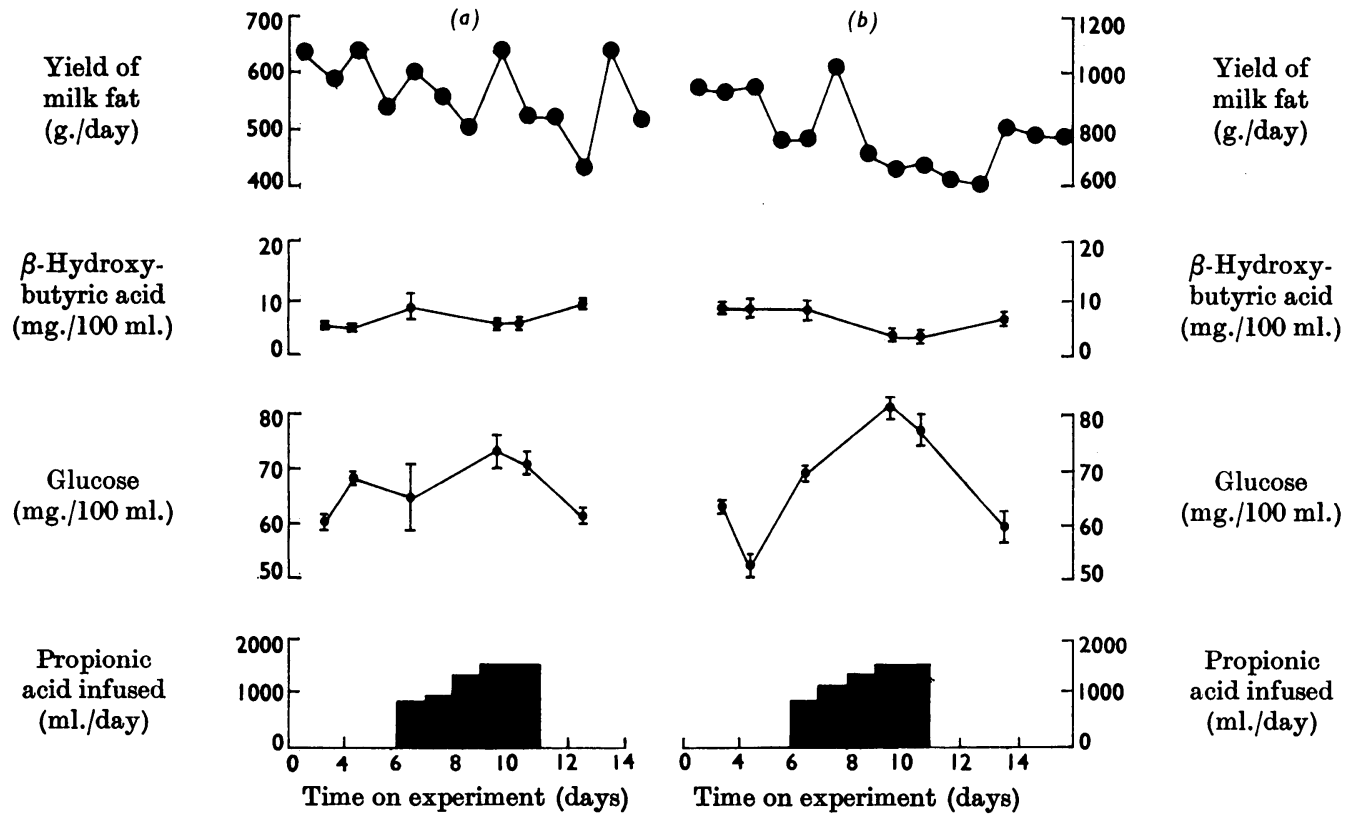

Fig. 1. Effect of intraruminal infusions of propionic acid on the yield of milk fat and on the concentrations of $\beta$-hydroxybutyric acid and glucose in the blood plasma. Experimental details are given in the text. (a) Cow 8; (b) cow 9. 
butyric acid. The daily yield of fat, however, was unaltered in cow 9 by the infusion of butyric acid (mean percentage change, $+1 \cdot 2 \pm 8 \cdot 8$ ) whereas it tended to be depressed with the infusion of propionic acid (mean percentage change, $-9 \cdot 6 \pm 7 \cdot 1$ ), but with cow 8 the infusion of butyric acid markedly increased the fat yield (mean percentage change, $+13 \cdot 4 \pm 3 \cdot 8$ ) and the infusion of propionic acid was without effect
Yield of milk fat (g./day)

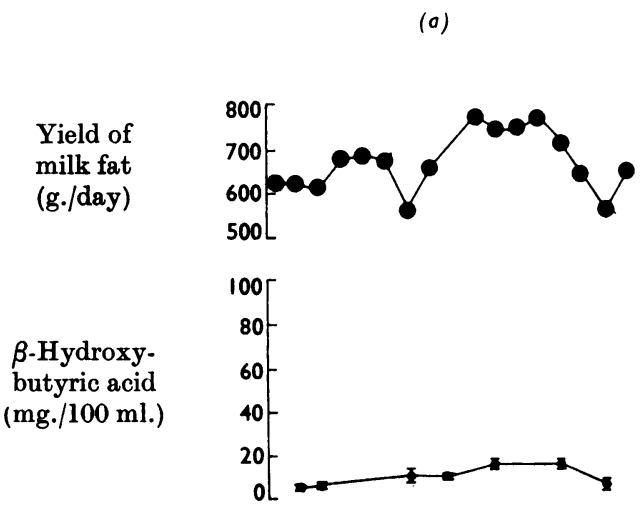

Glucose (mg./100 ml.)

Butyric
acid infused
(ml./day) (a)
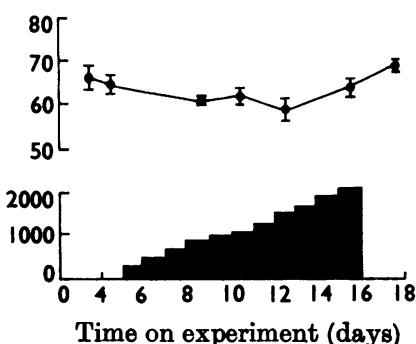

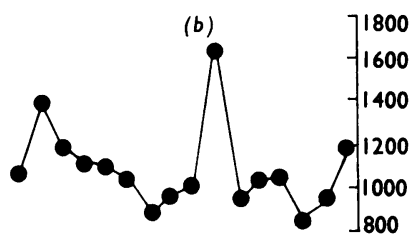

Yield of milk fat (g./day)
$B$-Hydroxybutyric acid (mg./100 ml.)

Glucose (mg./100 ml.)

Butyric acid infused (ml./day)

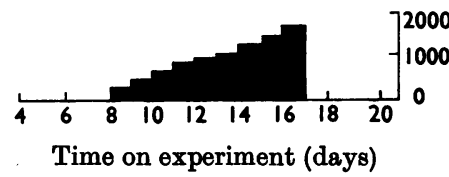

Fig. 2. Effect of intraruminal infusions of butyric acid on the yield of milk fat and on the concentrations of $\beta$-hydroxybutyric acid and glucose in the plasma. Experimental details are given in the text. (a) Cow 8; (b) cow 9 .

Table 3. Effects of intraruminal infusions of acetic acid, of propionic acid and of butyric acid on the concentrations of the four major fractions of lipids in the plasma of lactating cows

Experimental details are given in the text. Values are given as the means \pm s.r.M.

$\begin{array}{clc}\text { Cow } & \text { Infusion given } & \begin{array}{c}\text { Cholesterol esters } \\ \text { (mg./100ml.) }\end{array} \\ 1 & \text { Water only } & 170 \pm 38 \cdot 4 \\ & \text { Butyric acid } & 158 \pm 15 \cdot 1 \\ 2 & \text { Water only } & 178 \pm 19 \cdot 8 \\ & \text { Butyric acid } & 194 \pm 29 \cdot 6 \\ 3 & \text { Water only } & 178 \pm 21 \cdot 5 \\ & \text { Butyric acid } & 174 \pm 24 \cdot 7 \\ 1 & \text { Water only } & 151 \pm 3 \cdot 4 \\ & \text { Propionic acid } & 131 \pm 18 \cdot 3 \\ 2 & \text { Water only } & 192 \pm 45 \cdot 1 \\ & \text { Propionic acid } & 190 \pm 4 \cdot 9 \\ 3 & \text { Water only } & 173 \pm \mathbf{5 7 \cdot 1} \\ & \text { Propionic acid } & 159 \pm 10 \cdot 7 \\ 1 & \text { Water only } & 151 \pm 3 \cdot 4 \\ & \text { Acetic acid } & 152 \pm \mathbf{3 \cdot 5} \\ 2 & \text { Water only } & 192 \pm 45 \cdot 0 \\ & \text { Acetic acid } & 197 \pm \mathbf{3 \cdot 3}\end{array}$

Free cholesterol
$(\mathbf{m g} \cdot / 100 \mathrm{ml}$.
$23 \cdot 3 \pm 5 \cdot 43$
$22 \cdot 7 \pm 3 \cdot 64$
$25 \cdot 3 \pm 2 \cdot 60$
$28 \cdot 5 \pm 1 \cdot 81$
$27 \cdot 1 \pm 1 \cdot 27$
$29 \cdot 1 \pm 1 \cdot 35$
$24 \cdot 1 \pm 1 \cdot 01$
$29 \cdot 6 \pm 0 \cdot 57$
$29 \cdot 6 \pm 0 \cdot 50$
$26 \cdot 8 \pm 2 \cdot 93$
$24 \cdot 4 \pm 1 \cdot 54$
$28 \cdot 5 \pm 2 \cdot 45$
$24 \cdot 1 \pm 1 \cdot 01$
$22 \cdot 8 \pm 1 \cdot 00$
$29 \cdot 6 \pm 0 \cdot 50$
$26 \cdot 1 \pm 1 \cdot 1$

\begin{tabular}{|c|c|}
\hline $\begin{array}{l}\text { Triglycerides } \\
\text { (mg./100 ml.) }\end{array}$ & $\begin{array}{l}\text { Phospholipid } \\
\text { (mg./100 ml.) }\end{array}$ \\
\hline $\begin{array}{l}4 \cdot 3 \pm 1 \cdot 50 \\
3 \cdot 7 \pm 1 \cdot 31\end{array}$ & $\begin{array}{r}117 \pm 34 \cdot 1 \\
85 \pm 8 \cdot 0\end{array}$ \\
\hline $\begin{array}{l}6 \cdot 4 \pm 2 \cdot 02 \\
7 \cdot 4 \pm 2 \cdot 35\end{array}$ & $\begin{array}{l}116 \pm 11 \cdot 9 \\
121 \pm 6 \cdot 7\end{array}$ \\
\hline $\begin{array}{l}7 \cdot 1 \pm 0.57 \\
3 \cdot 6 \pm 0 \cdot 71\end{array}$ & $\begin{array}{l}126 \pm 9 \cdot 0 \\
127 \pm 1 \cdot 4\end{array}$ \\
\hline $\begin{array}{l}5 \cdot 6 \pm 1 \cdot 07 \\
4 \cdot 4 \pm 0 \cdot 38\end{array}$ & $\begin{array}{l}98 \pm 11 \cdot 2 \\
95 \pm 25 \cdot 4\end{array}$ \\
\hline $\begin{array}{l}4 \cdot 4 \pm 0 \cdot 17 \\
4 \cdot 6 \pm 0 \cdot 95\end{array}$ & $\begin{array}{l}158 \pm 1 \cdot 6 \\
139 \pm 0 \cdot 8\end{array}$ \\
\hline $\begin{array}{l}2 \cdot 7 \pm 1 \cdot 05 \\
2 \cdot 4 \pm 0 \cdot 22\end{array}$ & $\begin{array}{l}122 \pm 2 \cdot 1 \\
106 \pm 1 \cdot 8\end{array}$ \\
\hline $\begin{array}{l}5 \cdot 6 \pm 1.07 \\
5 \cdot 5 \pm 0.85\end{array}$ & $\begin{array}{r}99 \pm 11 \cdot 2 \\
100 \pm 2 \cdot 1\end{array}$ \\
\hline $\begin{array}{l}4.4 \pm 0.17 \\
4 \cdot 2 \pm 0.22\end{array}$ & $\begin{array}{l}158 \pm 1.5 \\
120 \pm 6 \cdot 8\end{array}$ \\
\hline
\end{tabular}


(mean percentage change, $-0 \cdot 4 \pm 6 \cdot 3$ ). The observed changes in total fat yield are thus not closely dependent on associated changes in the concentrations of $\beta$-hydroxybutyrate or of glucose in blood plasma. Because of the large day-to-day variations in fat yield (a recognized problem inherent in the use of routine milking techniques) a statistical study of the relationship between milk-fat secretion and the concentrations of individual constituents in blood plasma was not practicable.

\section{Effects of infusions on lipid constituents of blood plasma}

No consistent effects of infusions of volatile fatty acids on the concentrations in the plasma of esterified or free cholesterol, triglycerides or phospholipids were observed (Table 3). There was considerable day-to-day variation in the concentrations of particularly the esterified cholesterol and phospholipid fractions.

\section{DISCUSSION}

The increases in the yield of milk fat that occur in the lactating cow in response to the intraruminal infusion of acetic acid or of butyric acid must result primarily from an increased synthesis and secretion of $\mathrm{C}_{4}-\mathrm{C}_{16}$ fatty acids. The associated decrease in the secretion of $\mathbf{C}_{18}$ acids is probably a compensatory change, which would result from an increase in the amount of $\mathrm{C}_{4}-\mathrm{C}_{16}$ acids in a common pool of fatty acids contributing to triglyceride formation in the mammary gland. The decrease in the yield of milk fat in response to the intraruminal infusion of propionic acid does not, however, result from simply the opposite of these changes: the secretion of palmitic acid is not affected and the secretion of all other major constituent acids, with the possible exception of lauric acid, is decreased.

Responses in milk-fat secretion to intraruminal infusions of volatile fatty acids are at a maximum within about 4 days of the introduction of an infusion, and by comparison with corresponding changes in the secretion of milk protein or in the yield of milk (Rook \& Balch, 1961) are rapid in development. It is therefore possible that the rate of synthesis of milk fat is sensitive to short-term variations in the concentration of its precursors in arterial blood. Because of technical difficulties, serial samples of mammary arterial blood cannot readily be obtained from milking cows, and in the present work it was assumed that variations in the concentrations of materials in arterial blood would be reflected in the composition of jugular venous blood, which can be readily sampled.

In a preliminary account (Storry \& Rook, 1961) of some of the present results, the suggestion was made that the decrease and the increase in the yield of milk fat brought about respectively by the infusion of propionic acid and of butyric acid might be related to the associated changes in the concentration of $\beta$-hydroxybutyrate in blood plasma, since $\beta$-hydroxybutyrate is a possible precursor of the short-chain fatty acids of milk fat (Kumar, Lakshmanan \& Shaw, 1959). Similarly, the increase in milk-fat yield in response to the infusion of acetic acid was attributed partly to the associated increase in the concentration of $\beta$-hydroxybutyrate in blood plasma but also, because of the known role of acetate in milk-fat synthesis (Cowie et al. 1951; Popják, French, Hunter \& Martin, 1951 ; Rogers \& Kleiber, 1957; Hardwick, Linzell \& Mepham, 1963), to the associated increase in the concentration of the latter in blood plasma.

That changes in the secretion of the fatty acids of milk fat with intraruminal infusions of propionic acid are not the opposite of those obtained with the infusions of butyric acid now excludes the possibility that the effects of these two acids can be entirely accounted for by an altered synthesis of fatty acids in response to a change in the concentration of precursor $\beta$-hydroxybutyrate. Of particular interest therefore is the observation by Vallance \& McClymont (1959) that intravenous infusions of glucose in a lactating cow depressed milk-fat secretion, and their suggestion that, since there was a concomitant depression in the concentration of plasma triglycerides and a decrease in the mammary arteriovenous difference (McClymont \& Vallance, 1962), the effect may have been due to a decreased synthesis of milk fat from triglycerides of the blood plasma. In support of this possibility there is now good evidence for the formation of more particularly the long-chain acids of milk fat from triglycerides of the chylomicra and the low-density lipoproteins of the blood plasma (Barry, Bartley, Linzell \& Robinson, 1963; Welch, Noble, Wright, Bishop \& Glascock, 1963; Lascelles, Hardwick, Linzell \& Mepham, 1964), and also the intravenous infusion of an emulsion of cotton-seed oil (Storry \& Rook, $1964 b$ ) has been shown to increase the secretion of milk fat.

The intraruminal infusion of propionic acid would presumably exert an effect similar to the intravenous infusion of glucose, since propionic acid is glucogenic in its metabolism and its infusion in lactating cows has invariably caused an increase in plasma glucose concentration. However, in the present experiments no depression in the concentration of plasma triglycerides was observed in response to the intraruminal infusion of propionic acid, but this may be due to the fact that in the cows examined the recorded concentrations of triglycerides were low and variable. Also, the changes in blood glucose concentration and in fat yield in response to the 
infusion of propionic acid were much smaller than those obtained by McClymont \& Vallance (1962) during the intravenous infusion of glucose. Smaller changes in plasma triglyceride concentration in response to the infusion of propionic acid might therefore be expected, and these would be difficult to detect. If it is assumed that the decrease in the secretion of $\mathrm{C}_{18}$ acids in response to the intraruminal infusion of propionic acid or to the intravenous infusion of glucose results from a diminished synthesis of these acids from plasma triglycerides, any decrease in the secretion of the short-chain fatty acids of milk fat could then reasonably be attributed to a decrease in the concentration of plasma $\beta$-hydroxybutyrate. The evidence of Kumar et al. (1959) is that $\beta$-hydroxybutyrate is incorporated into mainly the $\mathrm{C}_{4}-\mathrm{C}_{10}$ fatty acids of milk fat. Some explanation, however, is then required for the marked increase in the yield of palmitic acid obtained in response to the intraruminal infusion of butyric acid. One possibility would be that the metabolism of butyrate in the liver gives rise to acetate (Annison et al. 1963) and thus promotes the incorporation of acetate into milk fat. But in the present experiments a net conversion of butyrate into acetate in the liver was not indicated, since the concentration of acetate in peripheral blood was unaltered by the intraruminal infusion of butyric acid, and Rook et al. (1965) have already shown that intraruminal infusions of butyric acid have a more marked effect on fat yield than do infusions of acetic acid, and that when the infusions are given together the effects are additive.

The increased secretion of the $\mathrm{C}_{4}-\mathrm{C}_{16}$ acids observed with the intraruminal infusion of acetic acid is consistent with the hypothesis suggested previously (Storry \& Rook, 1961) of an increased synthesis of fatty acid from acetate due to the increased concentration of acetate in peripheral blood.

We are grateful to Dr A. T. Cowie for the cannulation of the jugular vein in the initial experiments and to $\mathrm{Mr} \mathbf{A}$. J. Hall, Mr V. Johnson, Mr D. Millard, Mrs M. Ritchie and $\mathrm{Mr}$ B. Tuckley for technical assistance.

\section{REFERENCES}

Annison, E. F., Hill, K. J. \& Lewis, D. (1957). Biochem. J. 66, 593.

Annison, E. F., Leng, R. A., Lindsay, D. B. \& White, R. R. (1963). Biochem. J. 88, 248.

Armstrong, D. G. \& Blaxter, K. L. (1957). Brit.J. Nutr. 11, 247.

Barker, S. B. \& Summerson, W. H.(1941). J.biol.Chem.138, 535.
Barron, E. J. \& Hanahan, D. J. (1958). J. biol. Chem. 231, 493.

Barry, J. M., Bartley, W., Linzell, J. L. \& Robinson, D. S. (1963). Biochem. J. 89, 6.

Brown, W. D. (1959). Aust. J. exp. Biol. med. Sci. 37, 523.

Carroll, K. K. (1961). Nature, Lond., 191, 4786.

Chen, P. S., Toribara, T. Y. \& Warner, H. (1958). Analyt. Chem. 28, 1756.

Clarke, R. \& Malan, J. R. (1956). Onderstepoort J. vet. Res. 27, 101.

Cowie, A. T., Duncombe, W. G., Folley, S. J., French, T. H., Glascock, R. F., Massart, L., Peeters, G. \& Popják, G. (1951). Biochem. J. 49, 610.

Dole, V. P., James, A. T., Webb, J. P. N., Rizack, M. A. \& Sturman, M. F. (1959). J. clin. Invest. 38, 1544.

Folch, J., Lees, M. \& Sloane-Stanley, G. H. (1957). J. biol. Chem. 226, 497.

Friedman, T. E. \& Haugen, G. E. (1943). J. biol. Chem. 147, 415.

Hardwick, D. C., Linzell, J. L. \& Mepham, T. B. (1963). Biochem. J. 88, 213.

Hueter, F. G., Shaw, J. C. \& Doetsch, R. N. (1956). J. Dairy Sci. 89, 1430.

Johnson, R. B. (1955). Cornell Vet. 45, 273.

Kumar, S., Lakshmanan, S. \& Shaw, J. C. (1959). J. biol. Chem. 234, 754.

Lascelles, A. H., Hardwick, D. C., Linzell, J. L. \& Mepham, T. B. (1964). Biochem. J. 92, 36.

Leng, R. A. \& Annison, E. F. (1963). Biochem. J. 86, 319.

McArdle, B. (1955). Biochem. J. 60, 647.

McClymont, G. L. \& Vallance, S. (1962). Proc. Nutr. Soc. 21, xli.

Metcalfe, L. D. \& Schmitz, A. A. (1961). Analyt. Chem. 33, 363.

Moore, J. H. (1962). J. Dairy Res. 29, 141.

Moore, J. H. \& Doran, B. M. (1962). Biochem. J. 84, 506.

Pennington, R. J. \& Sutherland, T. M. (1956). Biochem. J. 63, 353.

Popják, G., French, T. H., Hunter, C. D. \& Martin, A. J. P. (1951). Biochem. J. 48, 612.

Reid, R. L. (1960). Analyst, 85, 265.

Rogers, T. A. \& Kleiber, M. (1957). Proc. Soc. exp. Biol., N.Y., 84, 705.

Rook, J. A. F. \& Balch, C. C. (1961). Brit. J. Nutr. 15, 361.

Rook, J. A. F., Balch, C. C. \& Johnson, V. W. (1965). Brit. J. Nutr. 19, 93.

Scarisbrick, R. (1952). Biochem. J. 50, xxxiv.

Schultz, L. H. \& Smith, V. R. (1951). J. Dairy Sci. 34, 1191.

Somogyi, M. (1952). . J. biol. Chem. 195, 10.

Storry, J. E. \& Millard, D. (1965). J. Sci. Fd Agric. (in the Press).

Storry, J. E. \& Rook, J. A. F. (1961). Biochim. biophys. Acta, 48, 610 .

Storry, J. E. \& Rook, J. A. F. (1964a). Nature, Lond., 201, 926.

Storry, J. E. \& Rook, J. A. F. (1964b). Biochem. J. 91, 27 c.

Vallance, S. \& McClymont, G. L. (1959). Nature, Lond., $183,466$.

Waldo, D. R. \& Schultz, L. H. (1960). J. Dairy Sci. 43, 496.

Welch, V. A., Noble, R. C., Wright, E. W., Bishop, C. \& Glascock, R. F. (1963). Biochem. J. 87, 32P. 